\title{
MODELS OF INTERACTION BETWEEN EDUCATION, SCIENCE, INNOVATION AND PRODUCTION IN THE THEORY GRAPH THEORY
}

\author{
Sofia Diakonova1, Stepan Artyshchenko², Lyudmila Shevchenko ${ }^{3}$, Olga \\ Tsaregorodtseva ${ }^{4}$ \\ ${ }^{1}$ Candidate of technical Sciences, Associate Professor, Voronezh State Technical University, 20 \\ years of October street, 84, Voronezh, Russia, E-mail: sof1355@yandex.ru \\ ${ }^{2}$ Candidate of physics and mathematics Sciences, Associate Professor, Voronezh State Technical \\ University, 20 years of October street, 84, Voronezh, Russia, E-mail: art.stepan@mail.ru \\ ${ }^{3}$ Candidate of Economic Sciences, Associate Professor, Voronezh State Technical University, 20 \\ years of October street, 84, Voronezh, Russia, E-mail: shevl21@yandex.ru \\ ${ }^{4}$ Senior Lecturer, Voronezh State Technical University, 20 years of October street, 84, Voronezh, \\ Russia, E-mail: oi@yandex.ru
}

\begin{abstract}
The aim of the presented work is to substantiate the key role of the university as a generator and aggregator of scientific, educational, production and innovation processes. Currently, in modern works describing the development and interaction of science, education and innovation, the main model is the triangle model, where they are located at its vertices. According to the authors, for a complete description of real processes in the mentioned area, the model of this triangle is not enough, since it does not take into account the interrelationships of science, education and innovation with production. Therefore, in this work, the authors propose several other models that more fully describe the processes and relationships in this area, and in particular, the problem of combining the educational environment with production is solved. The main triangle model and other models presented by the authors are proposed to be investigated in this paper on the basis of graph theory.
\end{abstract}

Keywords: education, innovation, science, university, manufacturing, graph theory, models.

\section{INTRODUCTION}

Recently, the theory of diffusion of innovations has attracted great interest in the study of innovation processes. It finds practical application in a wide range of scientific disciplines: primarily in economics, mass communications, sociology, social anthropology, marketing, geography, and even medicine.

In the process of studying diffusion, it was found that there are certain patterns, including the innovation itself, the transfer of information from one subject to another in terms of a community or social environment, and all these components are subject to a time factor.

According to the theory of diffusion of innovations, any innovation (for example, a new idea, technique, technology) diffuses, i.e. spreads in society according to a certain predictable pattern.

Another remarkable property of the innovation process is self-organization, which stems from the nonlinear nature of innovation. Thanks to self-organization, innovations do not act alone, but, as a rule, in groups and forming so-called "clusters". Innovations within one cluster mutually reinforce each other, causing a synergistic effect.

It is thanks to the synergistic effect of the interaction of innovations within the cluster that they cause a powerful cumulative growth of the economy, providing a breakthrough nature of its development. Clusters of basic technologies lead to the emergence of new industries and, thus, launch long economic cycles, forming an upward stage of the "Kondratieff cycle," which reaches its peak at the moment of maturation of 
innovations. The aggregate of clusters of basic innovations forms a technological paradigm.

\section{DISCUSSION AND RESULTS}

The diffusion of innovations takes place simultaneously in two spaces: social and territorial (geographic). In reality, these spaces overlap. In this case, it makes sense to talk about social spaces (inclusions) within the city. But, the patterns of processes in them are different.

For further use in diagrams, figures and abbreviations, we introduce the following designations:

$\mathrm{S}$ - science;

E - education;

I - innovation;

$\mathrm{P}$ - production;

$\mathrm{U}$ - university.

Currently, in well-known modern works and models describing the development and interaction of science, education and innovation, the model of the S-E-I triangle, where science, education and innovation are located at its vertices, is very relevant and fashionable (Fig. 1). According to the authors, for a complete description of real processes in the mentioned area, the model of this triangle is not enough and, accordingly, the mutual relations of science, education and innovation with production are not taken into account.

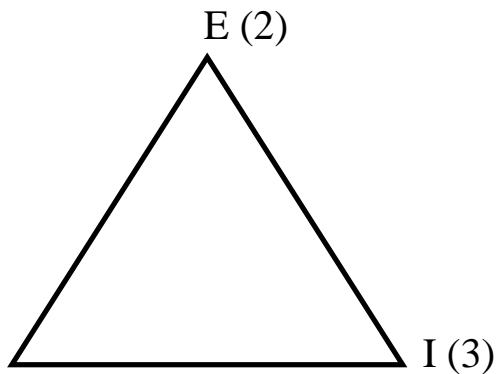

Fig. 1. Triangle model S-E-I

At the same time, the model of the S-E-I triangle does not take into account the independent role of the university as a generator and aggregator of scientific, educational and innovative (as well as production processes).

Therefore, in this work, the authors propose several other models that more fully describe the processes and relationships in this area.

We will briefly list them and give pictures:

1. Bearing in mind the flat (planar) model, instead of the S-E-I triangle, it is more expedient to consider the S-E-I-P quadrangle (Fig. 2).

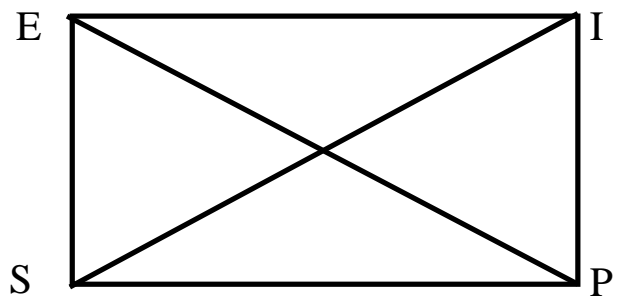

Fig. 2. Quadrangle model S-E-I-P

The triangle model does not take into account the relationship with production and the mutual influence of all elements, therefore, another model is proposed that takes into account the interaction with production and is represented in the form of not a triangle, but a square or rhombus, which connects S-E-I-P and can be represented and formalized as undirected (since the connections between the vertices are in both directions) 
graph, at the vertices of which are S-E-I-P.

2. Even if we take the triangle model as a basis, it is advisable to modify it into a spatial pyramid model (Fig. $3)$, where the university is located at the apex above the S-E-I triangle as a generator and aggregator of the corresponding limits.

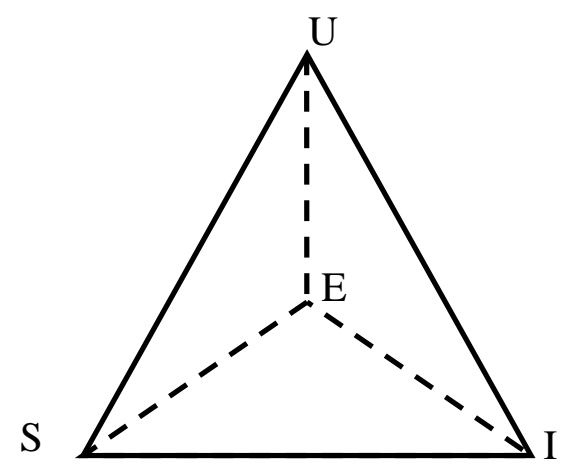

Fig. 3. Spatial model of a pyramid with a triangle S-E-I at the base

3. Taking as a basis the model of the quadrilateral S-E-I-P proposed in paragraph 1, along with the advantages that it has over the model of a triangle, it is also advisable to modify it into a spatial model of a pyramid (Fig. 4), where in the fifth the university is located at the top of the quadrangle S-E-I-P.

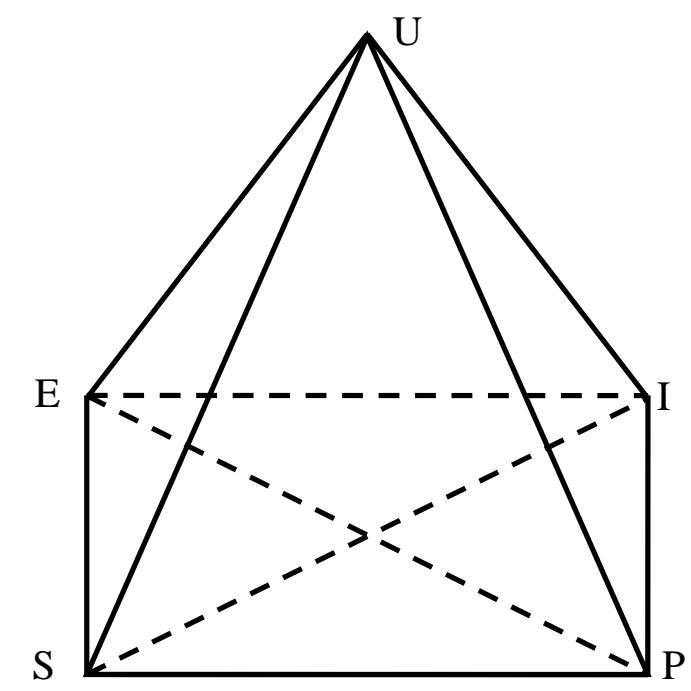

Fig. 4. Spatial model with a quadrangle S-E-I-P at the base

Next, we will analyze the above models and identify the advantages of some of them.

It is quite natural and expedient to turn to graph theory in this case.

The model in item 1 corresponds to the graph:

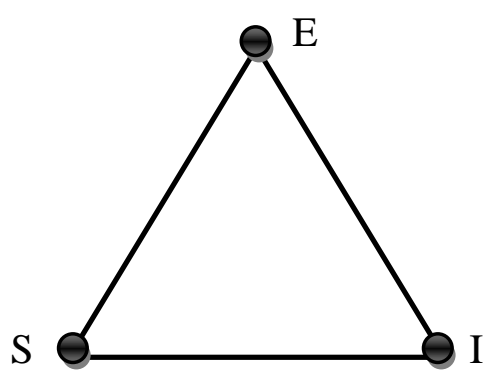

Fig. 5. Graph S-E-I 
The model in item 1 corresponds to the graph:

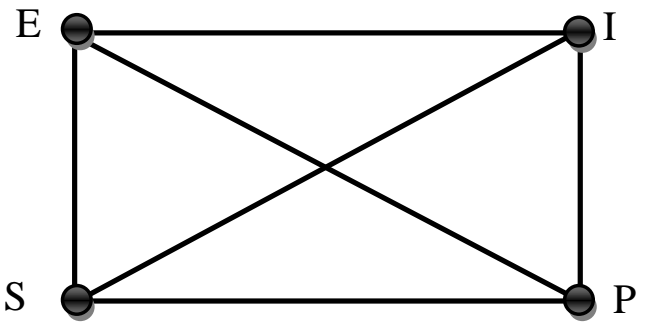

Fig. 6. Graph S-E-I-P

Model in number 2 corresponds to a planar graph:

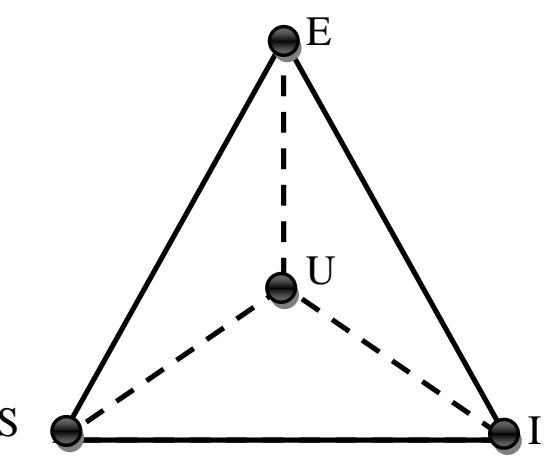

Fig. 7. Planar graph S-E-I with center U

The model in paragraph 3 corresponds to the graph:

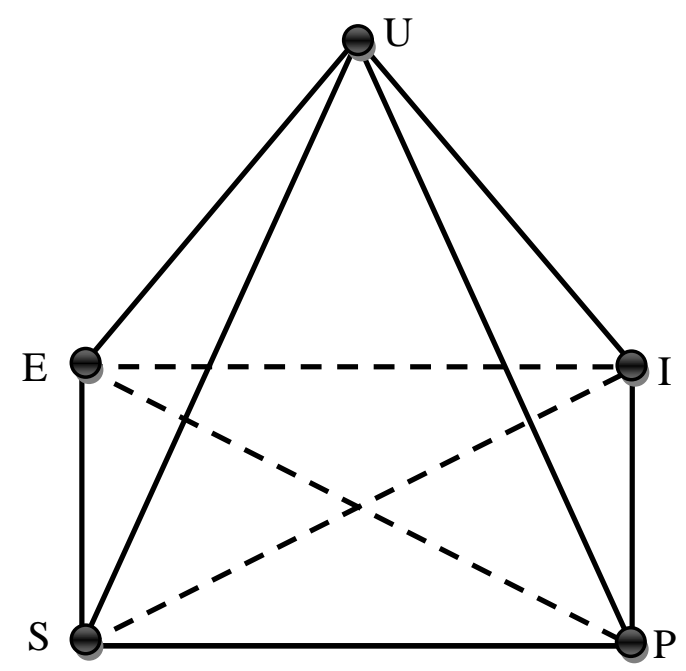

Fig. 8. A graph with a rectangular base S-E-I-P

This graph cannot be represented on a plane without intersecting edges, that is, this graph is not planar, but three-dimensional, which determines its properties and features, as well as the potential possibilities of its use to describe complex systems.

For the graph corresponding to the original model of the S-E-I triangle, in accordance with Fig. 1. the adjacency matrix is:

$$
A=\left(\begin{array}{lll}
0 & 1 & 1 \\
1 & 0 & 1 \\
1 & 1 & 0
\end{array}\right),
$$


For the graph corresponding to the model of the quadrilateral S-E-I-P, considered in $p .1$, in accordance with Fig. 2

$$
A=\left(\begin{array}{llll}
0 & 1 & 1 & 1 \\
1 & 0 & 1 & 1 \\
1 & 1 & 0 & 1 \\
1 & 1 & 1 & 0
\end{array}\right),
$$

For a graph corresponding to a pyramid model with a base triangle S-E-I, in accordance with Fig. 3. the adjacency matrix has the form:

$$
A=\left(\begin{array}{llll}
0 & 1 & 1 & 1 \\
1 & 0 & 1 & 1 \\
1 & 1 & 0 & 1 \\
1 & 1 & 1 & 0
\end{array}\right),
$$

For the graph corresponding to the pyramid model with the base of the S-E-I-P quadrilateral in accordance with Fig. 8. the adjacency matrix is:

$$
A=\left(\begin{array}{lllll}
0 & 1 & 1 & 1 & 1 \\
1 & 0 & 1 & 1 & 1 \\
1 & 1 & 0 & 1 & 1 \\
1 & 1 & 1 & 0 & 1 \\
1 & 1 & 1 & 1 & 0
\end{array}\right)
$$

\section{CONCLUSION}

Let's continue the analysis of the proposed models. The presented graphs are undirected graphs, in addition, they are among the so-called connected graphs, as well as complete graphs.

The graphs corresponding to Fig. - a model of a triangle to a figure (model of a triangular pyramid) and even a graph corresponding to Fig. (quadrilateral model) are planar graphs, since they can be represented on a plane without crossing the edges. This can be done even for a graph corresponding to a NOPP quadrangle with intersecting diagonals, removing one of the diagonals and making this graph planar.

And as already mentioned above, the graph corresponding to the model of the quadrangular pyramid, where the university is located at the fifth vertex, is not planar, since can in no way be represented on a plane without intersecting edges. This graph is three-dimensional.

In accordance with the above, it has certain features and the possibility of using it to describe complex systems, which will be analyzed in further works of the authors. In the future, it is advisable to analyze the models and graphs presented in this paper, as well as to additionally classify the considered graphs, for example, by examining the presence of Euler, Hamiltonian cycles in them, writing down the incidence matrices and, on the basis of this, draw additional conclusions and give additional recommendations, i.e. formalize this task more fully.

These areas are very promising for solving the problems of combining the educational environment with production and will be developed in the subsequent works of the authors.

\section{REFERENCE LIST}

Cristiano Franceschinis, Mara Thiene, Riccardo Scarpa, John Rose, Raffaele Cavalli. (2017) Adoption of renewable heating systems: An empirical test of the diffusion of innovation theory. Energy. № 12515 Pp. 313-326. (in Engl).

Dalwoo Nam, Junyeong Lee, Heeseok Lee. (2019) Business analytics adoption process: An innovation diffusion perspective. International Journal of Information Management. № 49. Pp. 411-423.. (in Engl).

Diakonova S., Artyshchenko S., Sysoeva D., Surovtsev I. (2020) Stady of periodic proctsses of changing the namber of innovations in relation to Kondratiev cycles. In the collection: E3S Web of Conferences. Key Trends in Transportation Innovation. (in Engl).

Dorian-Laurentiu Florea. (2015) The Relationship between Branding and Diffusion of Innovation: $A$ 
Systematic Review Procedia Economics and Finance. № 23. Pp. 1527-1534. (in Engl).

Dyakonova S.N., Artyshchenko S., Sysoeva D.V., Surovtsev I.S., Karpovich M.A. (2020) On the application of the thermal conductivity equation to describe the diffusion process. In the collection: E3S Web of Conferences. XIII International Scientific and Practical Conference "State and Prospects for the Development of Agribusiness - interagromash 2020". (in Engl).

Jens Clausen, Klaus Fichter. (2019) The diffusion of environmental product and service innovations: Driving and inhibiting factors. № 31. Pp. 64-95. (in Engl).

Keiichi Kishi. (2019) Technology diffusion, innovation size, and patent policy European Economic Review № 118. Pp. 382-410. (in Engl).

Maria A.Halbinger. (2018) The role of makerspaces in supporting consumer innovation and diffusion: An empirical analysis Research Policy. № 47, Issue 10. Pp. 2028-2036. (in Engl).

Matthew A. Douglas, Robert E. Overstreet, Benjamin T. Hazen. (2016) Art of the possible or fool's errand? Diffusion of large-scale management innovation Business Horizons. № 59, Issue 4. Pp. 379-389. (in Engl).

Melissa Raynard. Understanding Academic (2017) E-books Through the Diffusion of Innovations Theory as a Basis for Developing Effective Marketing and Educational Strategies The Journal of Academic Librarianship № 43, Issue 1. Pp. 82-86. (in Engl).

Mokter Hossain, Henri Simula, Minna Halme. (2016) Can frugal go global? Diffusion patterns of frugal innovations. Technology in Society. № 46. Pp. 132-139. (in Engl).

Rainer Andergassen, Franco Nardini, Massimo Ricottilli. (2017) Innovation diffusion, general purpose technologies and economic growth. Structural Change and Economic Dynamicsю № 40. Pp. 72-80. (in Engl).

Sanjesh Kumar, Baljeet Singh. (2019) Barriers to the international diffusion of technological innovations. Economic Modelling. № 82 .Pp. 74-86. (in Engl).

Sobia Mannan, Shahrina Md Nordin, Shameem Rafik-Galea, Ammar Redza Ahmad Rizal. (2017) The ironies of new innovation and the sunset industry: Diffusion and adoption. Journal of Rural Studies. № 55. Pp. 316-322. (in Engl).

Stephen L. Vargo, Melissa Archpru Akaka, Heiko Wieland. (2020) Rethinking the process of diffusion in innovation: A service-ecosystems and institutional perspective. Journal of Business Research In press, corrected proof Available online 5. (in Engl).

Xiaoqun Zhang. (2018) Frugal innovation and the digital divide: Developing an extended model of the diffusion of innovations. International Journal of Innovation Studies № 2, Issue 2. Pp. 53-64. (in Engl).

Ershov B.A. (2010) The Russian Orthodox Church and secular power in the Voronezh province in the XIX early XX centuries. GOU VPO "Voronezh State Technical University". Voronezh. 167 p. (in Russ).

Ershov B.A. (2010) The system of spiritual education in Voronezh province in the 19th century. Education and Society. №. 5 (64). Pp. 105-108. (in Russ).

Ershov B.A., Fursov V.N. (2018) The Russian Church in the State Mechanism of Russia. Bulletin SocialEconomic and Humanitarian Research. № 1. Pp. 32-37. (in Engl).

Ershov B.A., Perevozchikova L.S., Romanova E.V. (2019) Globalization and Intensification of Spiritual Values in Russia in the Philosophical Aspect. 6th International Conference on Education and Social Sciences Abstracts \& Proceedings. Pp. 208-212. (in Engl).

Ershov B.A., Perevozchikova L.S., Romanova E.V., Ashmarov I.A. (2019) The Concept of Spirituality in Social Philosophy. Smart Innovation, Systems and Technologies. T. 139. Pp. 688-694. (in Engl). 